\title{
Form And Anatomy of The Branding Outlet Agreement (Cooperation between PT. Surya Madistrindo and Legita Café)
}

\author{
Tri Andari Dahlan ${ }^{1}$ \\ \{triandaridahlan@mail.unnes.ac.id\} \\ ${ }^{1}$ Faculty of Law , Semarang State University, Semarang, Indonesia
}

\begin{abstract}
Branding is a marketing strategy tool for industrial companies. Doing branding, means companies need cooperation with other parties. PT. Surya Madistrindo carries out cooperation in the form of a branding outlet agreement with Legita Café, this agreement was made and signed on 27 July 2018 and ends on 10 November 2019. In the implementation, the branding outlet agreement between PT. Surya Madistrindo did not run smoothly due to the lack of good draft agreements both anatomically and substance hence the contents of the agreement were unclear and multiple interpretations. The Legita Café is also not careful in making and studying agreements so that the achievements carried out by Legita Café include the implementation of imperfect achievements so that the Legita Café is categorized as having done a default.
\end{abstract}

Keywords: Agreement, Forms, Anatomy, Branding Outlet

\section{Introduction}

Indonesia is a developing country, this can be marked by its developments in economic sector. Increasingly intense business competition require strategic business able to compete. Because it is necessary to have a strategy in the form of product branding so that the wider community knows the product so that product sales will increase. Branding is built by many factors and is communicated through aspects of integrated marketing communication such as through advertisements, events, or promotions.[1]

The company's business to expand marketing and optimize sales is by product branding. Branding is an effective marketing strategy tool and has often been used by industrial companies. Branding is considered able to influence consumers to choose the product compared to other competing products. Sometimes we encounter outlets that are designed with the product wall brand. The wall brand is a branding outlet strategy to introduce and encourage consumers to buy the product. Business actors branding their trademarks by using other people's outlets with an agreement called a branding outlet .

Business strategies in the form of branding outlets are outlined in the form of a cooperation agreement. This cooperation agreement was born based on the principle of freedom of contract. This principle contains a view that people are free to do or not do agreements, free with whom to do or not do agreements, free with whom they enter into agreements, free about what is promised, and free to set conditions for the agreement.[2] 
PT. Surya Madistrindo is a company owned by PT. Gudang Garam Tbk. which responsible to handle the distribution of Gudang Garam products. PT. Surya Madistrindo uses a variety of strategies to do marketing Gudang Garam products to be able to compete with other cigarette company products. PT. Surya Madistrindo has 12 offices regional representatives and 180 offices scattered areas throughout Indonesia. In carrying out marketing functions, each area office has its own marketing strategy thus consumers are interested in the products of PT. Gudang Garam Tbk. One of the strategies in marketing PT. Surya Madistrindo Pekalongan Regional Office Area is a joint branding outlet .

Legita Cafe is a coffee shop domiciled at Ruko Grand Comal Purwosari, Jl. Ahmad Yani, Comal, Pemalang. Legita Cafe is a famous cafe among teenagers because everyday the consumers are mostly teenagers. Legita Cafe was chosen by PT. Surya Madistrido to be one of the sponsor for PT. Gudang Garam Tbk products.

Based on the results of the assessment, PT. Surya Madistrindo offers cooperation to Legita Cafe in the form of a Branding Outlet Cooperation . In this outlet branding agreement, Legita Cafe is willing to provide a place outside and inside the outlet for sponsorship so PT. Madya Madistrindo can place branding material. In the contents of the branding agreement, Legita Cafe has also agreed to sell products owned by PT. Gudang Garam in sufficient quantities to meet consumer needs, including the launch of new products. Legita Cafe has also agreed to hold the event twelve times in the period according to the agreement period. But until the agreement ends, Legita Cafe cannot compliance their event in accordance of agreement.

\section{Method}

The method used in this study is to use a qualitative approach to the type of empirical juridical research. Data sources used are primary data sources and secondary data sources. Data collection techniques are by interview, documentation, and observation. In testing the validity of the data, this study uses a triangulation technique with the source that is comparing the observational data with interview data and comparing the results of the interview with a related document.

\section{Results and Discussion}

\subsection{Form of Branding Outlet Agreement between PT. Surya Madistrindo with Legita Café}

Form agreement can be divided into two kinds, such as the written agreements and verbal agreements. A written agreement is an agreement made by the parties in written form, while verbal agreement is an agreement made by the parties in oral form (sufficiently enough if both parties agree). This branding outlet cooperation agreement is included in a reciprocal agreement because it contains rights on one of the parties, and the rights are at the same time an obligation for the other party. In this agreement, Legita Café has the right to get cooperation funds from PT. Surya Madistrindo if Legita Cafe willing to provide a branding place and held events as agreed in the agreement. This outlet branding agreement is also doesn't legally known, because it is not regulated in Indonesian Civil Code. This agreement is a result of development and community needs. 


\subsection{Agreement (toesteming or permission) of both parties.}

An agreement is a conformity of statement of will in between one or more people with another party. The first condition of the agreement is considered valid is the agreement of those who bind themselves [2]. PT. Surya Madistrindo and Legita Café come into a cooperation agreement we could viewed from the bidding process until the implementation of the agreement we couldn't found any coercion between the two parties. Because PT. Surya Madistrindo offers cooperation in the form of a branding outlet agreement that is mutually beneficial to both parties and the offer of cooperation is well received by the owner of Legita Cafe.

\subsection{Prowess ability. Prowess are the skills or abilities to do legal actions.}

Legal actions are actions that will have legal consequences. The people who will enter into an agreement must be capable and authorized people to carry out legal actions as stipulated in the legislation [2]. In making a letter of agreement, if one of the parties or the parties is an attorney / representative, then the reader must pay attention to whether or not the sentences have been included. It is important to include this formulation because it prevents disputes or disputes so as not to throw each other responsibility. The parties that made a branding outlet agreement between PT Surya Madistrindo and Legita Café were legal persons so that the terms of the agreement were valid, namely that they were fulfilled. In the agreement, PT. Surya Madistrindo was represented by Arif Setiawan as Regional Marketing Manager, while Legita Café was represented by Gideon Kurniawan Rahardjo as the owner of Legita Café.

\subsection{The object of the agreement (onderwero der overeenskomest).}

Performance is what is the debtor's obligation and what is the creditor's right [3]. According to the provisions of article 1234 of the Civil Code, achievements consist of giving something, doing something, not doing anything. The object of the branding outlet agreement between PT Surya Madistrindo and Legita Café is stated in the provisions of Article 6 which consists of giving something and doing something. PT. Surya Madistrindo, among others, is obliged to pay the agreed cooperation fund and is entitled to have full access and the right to supervise the material units at Legita Café. Then the rights and obligations of Legita Café, among others, are required to obtain prior permission at PT. Surya Madistrindo if using a Trademark in carrying out this agreement, Legita Café is entitled to a cooperation fund by PT. Surya Madistrindo, Legita Café is obliged to do work and sell products that have been determined by PT. Surya Madistrindo, Legita Café is also obliged to carry out the event 12 times according to the agreement of the parties, and must selling all material products of PT. Surya Madistrindo according to the agreement. In this case the condition of the object has been fulfilled.

\subsection{The existence of halal causa (geoorloofde oorzaak).}

In Article 1320 the Civil Code does not explain the meaning of geoorloofde oorzaak. Article 1337 of the Civil Code only lists prohibited causes. A cause is prohibited if it conflicts with law, decency, and public order [3]. This requirement has also been fulfilled by PT. Surya 
Madistrindo with Legita Café because in the contents of this outlet branding agreement there are no provisions that conflict with law and public order.

\subsection{Anatomy of a Branding Outlet Agreemen}

The inclusion of the title in the agreement is an indication of the main agreement agreed by the parties [4]. Branding outlet agreement between PT. Surya Madistrindo with Legita Cafe. The title of this agreement is " Legita Cafe Branding Outlet Agreement ". According to Satya Peloryandi Branding Outlet is an effort to present a brand somewhere or shop for people knowing the brand. However, in this outlet branding agreement, besides containing the obligation of Legita Café to provide a place for branding by PT. Surya Madistrindo and sells PT. Gudang Garam Tbk., Legita Cafe must also hold an event. Judging from the title, the obligation to hold an event is not appropriate to enter into a branding outlet agreement . It would be more appropriate if the event was made in a separate agreement and different title. The title made in the agreement must be clear and concise. By seeing the title of the agreement, people will immediately be able to imagine what things should be regulated in the agreement [4]

a. Opening. The opening in the agreement letter serves to show whether the agreement letter was made under or before a notary public, indicating where the agreement letter was made and the date the agreement was made. In the branding outlet agreement between PT. Surya Madistrindo with Legita Cafe, writing a complete and correct opening.

b. Comparison (The Parties). Comparison means the identity of the parties involved in making the agreement which includes the name, date and year of birth, address and position. Compilation is an indication that the parties have the right and authority (competent) to carry out legal actions. The compilation contains the function of explaining the identity of the parties making the agreement, in what position the person acts and based on what the position is.[4]. PT Surya Madistrindo and Legita Café have made a branding outlet agreement where the compilation is clearly written. PT Surya Madistrindo was represented by Arif Setiawan as Regional Marketing Manager while Gideon Kurniawan Raharjo was the owner of Legita Café.

c. Premise. The premise in the letter of agreement serves as a guide to the main discussion of the parties and the formulation of the reasons why an agreement was made [4]. In this case part of the premise has also been contained in a branding outlet agreement between PT. Surya Madistrindo with Legita Café.

d. Content of the Agreement. There is an important principle in the agreement one of which is the principle of Pacta Sun Servanda which reads all treaties made legally apply as a law for those who make them. so the parties involved in the agreement must pay close attention to and pay attention to all the provisions contained in the agreement to minimize the possibility of feeling disadvantaged in the future. Important elements in the contents of the agreement include:

\section{(1) Essential Elements}

This element is a must to be include on agreement. The essential element consists of the main object and the promised achievement. The basic terms of the one agreement with the other agreements vary depending on the type of agreement concerned.[4] An 
essential element of the branding outlet agreement between PT. Surya Madistrindo with Legita Cafe is the importance of branding by PT. Surya Madistrindo, the existence of branding material, the presence of Legita Café, the place to place the branding material, the cooperation costs, and the agreement period.

(2) Natural Elements

The natural element is an element that does not have to be in the agreement because even though the formulation or provisions are not included, it does not make the agreement made flawed and invalid so that it still has force to force and bind. If there is no natural element in an agreement, the law can be used as a guide in completing this natural element.[4]. Natural elements that can be seen in the branding outlet agreement between PT. Surya Madistrindo with Legita Café is an event conducted by Legita Café that does not contain activities that violate the norms of decency or moral norms that can result in the brand name of PT. Surya Madistrindo is not good in the eyes of the community and resulted in a decrease in product sales of PT. Surya Madistrido even though the agreement does not regulate what events can be held by Legita Café.

(3) Accidental Elements

Accidental element is inversely proportional to natural element because in accidental element, if something is not written in the agreement, the law does not appear to fill in the blanks because the law does not regulate it. And because the law does not regulate it nor is it stated in the agreement, it is not binding on the parties so there are no legal consequences.[4]. Accidental elements in the branding outlet agreement between PT. Surya Madistrindo with Legita Café. This element is considered incomplete and there are some unclear provisions. This can be seen in the provisions regarding rights and obligations which are basically a translation of the scope of the agreement, but in this agreement there are provisions regarding rights and obligations that are not regulated in the scope of the agreement. Then there are also conflicting provisions between the scope and rights and obligations.

In the scope of the agreement explained that PT. Surya Madistrindo has the exclusive right to do the work of branding a room in Legita Café, then the material unit will be placed outside and inside the outlet. So it can be seen that Legita Café is obliged to provide a place for PT. Surya Madistrindo to put the material unit in question. However, this matter is not explained in the provisions regarding rights and obligations because the provision of this place is the main thing needed in branding.

The provisions regarding the rights and obligations that must do the work are Legita Café There are provisions that conflict between rights and obligations with the scope of the provisions regarding the obligations to do the work. Within the scope of Article 2 paragraph 1 letter a it is explained that doing work is an obligation of PT. Surya Madistrindo but in the provisions of the rights and obligations in Article 6 paragraph (2) letter $\mathrm{c}$ the obligation to do work is an obligation of Legita Café. The provisions of the rights and obligations in this agreement also regulate the obligations of Legita Café in carrying out the event twelve times, but the provisions of the debut are not seen to be related to the scope of the agreement. The lack of relevance of some provisions in the agreement between the scope of the rights and obligations can cause the parties who read it do not understand and misinterpretation so that the agreement can not be implemented properly.

In the agreement, performance is a contractual obligation (contractual obligation) . These contractual obligations are from [5] :

1. Obligations determined by statutory regulations. 
2. Obligations agreed in the agreement.

3. Obligations required by propriety and customs.

Performance settled in Article 6 of the rights and obligations of PT. Surya Madistrindo and Legita Cafe. In this agreement the obligations that must be fulfilled by PT. Surya Madistrindo is paying cooperation funds to Legita Cafe and the rights that must be received by PT. Surya Madistrindo is entitled to have full access to and the right to supervise the unit of material at the outlet . In this case, PT. Surya Madistrindo has obtained its rights in the form of full access and has the right to supervise the material units in Legita Cafe.

Then, under Article 6, Legita Cafe must obtain prior permission from PT. Surya Madistrindo if it will use trademarks in carrying out this agreement with conditions to protect and maintain the integrity and good faith associated with trademarks, Legita Cafe must comply with the identity standards and instructions for use made by PT. Surya Madistrindo to use the trademark. PT. Surya Madistrindo has the right to review and give final approval on all plans to use the trade mark in whatever form and manner. If Legita Cafe uses the trademark of PT. Surya Madistrindo without the approval of PT. Surya Madistrindo, the Legita Cafe hereby releases PT. Surya Madistrindo of all responsibilities arising from the use of trademarks without such permission . Legita Cafe understands that all rights, ownership and interest in and goodwill inherent in trademarks, are and will always be the property of PT. Surya Madistrindo and Legita Cafe will not take or assist other parties to take actions that can interfere with, hinder, or reduce the rights, ownership and interests of PT. Surya Madistrindo in and for these trademarks. This provision has been implemented by Legita Café.

Another obligation that must be implemented by Legita Café is to held events twelve times in accordance with the agreement. These obligations have not been adhered to by Legita Cafe because Legita Cafe is only able to held such event five times.

This agreement is also said to be incomplete because in the provisions regarding the method of payment, it is explained that the payment phase must be preceded by the submission of documents from Legita Cafe, but the documents that must be submitted by Legita Cafe to PT. Surya Madistrindo is not explained in this agreement.

Then Legita Cafe has the right to pay cooperation funds by PT. Surya Madistrindo as referred to in Article 4 and Article 5 of this outlet branding agreement . In terms of payment, Legita Café has not yet received a full collaboration fund because there are stages in granting cooperation funds. Legita Café has just received a cooperation fund in the form of down payment with a nominal value of Rp.4,123,711. This down payment is given after Legita Café signs an agreement.

Payment of cooperation funds for phase I and phase II has not been paid by PT. Surya Madistrindo because the event has not been carried out in accordance with the

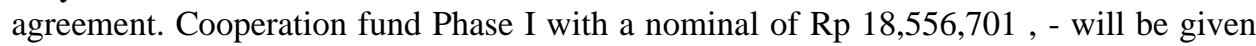
after Legita Cafe implement event six times. Phase II payments will also be given after Legita Cafe has conducted the event six times. However, these provisions are not contained in the agreement. This results in the reader being misinterpreted so that the agreement is not properly implemented.

Provisions regarding the termination of the agreement provided for in Article 9 are also not consistent between Article 9 paragraph (1) letter a and letter b. The provisions of Article 9 paragraph (1) letter a which explains that if there is an error or omission 
committed by Legita Café in the implementation of this agreement, then PT. Surya Madistrindo will give a warning to Legta Café to correct any mistakes or omissions that have been made and the warning must be carried out within 10 (ten) days after receiving the warning. While Article 9 paragraph (1) letter b explains that the agreement terminates if one party neglects or violates one of the agreements in the agreement. This unclear clause can cause the reader to be misinterpreted so that the implementation of the agreement cannot be carried out properly.

e. Closure (Cover). The letter of agreement usually states that the letter of agreement was made with the necessary copies / copies and also the agreement letter was signed by the representing parties and witnesses and affixed with a sheet. Branding outlet agreement between PT. Surya Madistrindo with Legita Cafe has been completed by the concluding part of the agreement which is deemed to have been completely made in duplicate and the parties' signature is affixed with official stamp.

\section{Conclusions}

Form agreement can be divided into two kinds, such as the written agreements and verbal agreements. A written agreement is an agreement made by the parties in written form, while verbal agreement is an agreement made by the parties in oral form (sufficiently enough if both parties agree).

The form of a branding outlet cooperation agreement between PT Surya Madistrindo and Legita Cafe is a written agreement, made under the hand without involving a notary public in making the agreement. This type of agreement is a reciprocal agreement and an anonymous agreement (innominat). The agreement has been made proportionally but in substance, there are still some unclear and unclear provisions that can cause misinterpretation. This agreement also contains essential, natural and accidental elements.

\section{Acknowledgments}

The author wishes to thank the Head of Semarang State University and Head of Faculty of Law for providing a facility to join International Conference in ICILS 3 UNNES.

\section{References}

[1] Astuti, Pirda Ariani Ambar: Membangun Merek Melalui Penyelenggaraan Sebuah Event: Studi Kasus pada Event "Sour Sally Just Wanna Have Fun”, Vol. 1 No. 2, pp.183. Jurnal Komunikasi. (2011).

[2] Adonara, Firman Fioranta: Aspek-Aspek Hukum Perikatan, pp. 91, 172, 180. Mandar Maju, Bandung. (2014)

[3] Harahap, Yahya : Segi-Segi Hukum Perjanjian, pp. 10, 18. Alumni. Bandung. (1986)

[4] Dwi Yuwono, Ismantoro: Baca Buku Ini Sebelum Tanda Tangan Surat Perjanjian, pp. 16, 18, 20,26, 32, 34. Pustaka Yustisia. Yogyakarta. (2013)

[5] Khairandy, Ridwan: Hukum Kontrak Indonesia, pp. 169. FH UII Press. Yogyakarta. (2013) 